\title{
Are Markov and semi-Markov Models Flexible Enough for Cognitive Panel Data?
}

Richard J. Kryscio 1,2,3* and Erin L. Abner ${ }^{2,3}$

${ }^{1}$ Department of Statistics, University of Kentucky, Kentucky, USA

${ }^{2}$ Department of Biostatistics, University of Kentucky, Kentucky, USA

${ }^{3}$ Sanders Brown Center on Aging, University of Kentucky Alzheimer's Disease Center, Kentucky, USA

\begin{abstract}
Markov chains and semi-Markov models are standard tools used to describe the flow of subjects from health into various stages of a disease. Applications of these techniques face challenges, when modeling the flow of elderly subjects through cognitive states into dementia, due to the interval censoring of the entry into cognitive states, the transient nature of pre-dementia cognitive states, time-dependent risk factors, missing data, selection bias, and clinical diagnoses that may not agree with the gold standard diagnoses obtained at autopsy. There is a need to make these tools more flexible, if they are to be used effectively, when analyzing cognitive panel data.

The purpose of this editorial is to discuss the use of Markov chains and semi-Markov processes to analyze panel data that routinely arise, when modeling the flow of elderly subjects from cognitively intact into impaired cognitive states, including various forms of Mild Cognitive Impairment $(\mathrm{MCl})$ and the absorbing state of dementia. While these approaches have been used successfully to model the flow of subjects through various health states associated with cancer and AIDS, their application to dementing diseases presents challenges not necessarily encountered in these other contexts.
\end{abstract}

\section{Panel Data}

Serial annual cognitive assessments minimize participant burden and practice effects, but introduce interval censoring, since conversions to impaired cognitive states occur between visits. The time interval between visits is often one year, but could be longer [1,2]. In addition, since these are elderly subjects, the effect of the competing risks of death and drop out is significant, and missed visits occur frequently. This is a natural setting for the use of semi-Markov models, since they can accommodate a mix of interval censoring for important transitions and exact times for deaths, as well as missed visits [3]. However, these applications have assumed that transitions are to the right (in one direction), and there are no time dependent covariates, such as strokes or late-life depression that might impact transitions $[4,5]$.

\section{Selection Bias}

Participants in panel studies may be asked to donate their brains upon death, and/or contribute serial cerebrospinal fluid samples, and/or undergo neuroimaging to help identify early biomarkers for the disease. Not all participants volunteer for these studies, which creates missing data/selection bias issues. Even without biomarkers, this bias frequently occurs since almost all panel studies are observational studies of volunteers, which creates a healthy cohort effect. For example, cohorts that do not allow seriously impaired elderly to enroll create significant bias, when identifying risks for transition to dementia [6].

\section{Classifying Cognitive States}

Dementia is currently incurable, and the dearth of therapy trial's success is not due to lack of effort or resources, but rather to the insidious nature of the underlying diseases. Recent data show that the Alzheimer's Disease (AD) process (thinning of the neuronal structure in the pre-frontal cortex of the brain) begins years prior to a clinical diagnosis of $\mathrm{AD}$, as evidenced by a heavier amyloid load observed in neuroimages of the brain decades, before dementia onset $[7,8]$. Therefore, current emphasis is on transitions into pre-dementia states, with the target being to identify and possibly treat groups of subjects who are at a high risk for mild impairments $[9,10]$.
There is little unanimity on the definition of an impaired state, with terms like age associated memory impairment, not seriously cognitively impaired, and MCI appearing in various studies. Even the currently popular MCI state has various definitions depending on the criteria used to define it (amnestic MCI, mixed MCI, MCI due to AD, etc.). Complex clinical criteria lead to MCI states that rarely involve backflow, while simpler criteria, such as poor performance on cognitive tests, lead to transient states with significant backflow between serial assessments [11] (Figure 1). This has serious modeling consequences, since only Markov chains are flexible enough to handle backflow.

The use of random effects in the Markov chain, first introduced by Salazar et al. [12], leads to issues related to estimating the random effects, when making predictions on the next subjects flow into and out of impaired MCI states. And even in these models, as Song et al. [13] demonstrated by introducing a scaling parameter into a random effects model for a Markov chain with backflow to show how to identify subjects who might undergo such reversions, multiple considerations remain. This approach can accommodate the use of time-dependent covariates, but this complicates the arithmetic, when studying the long run behavior of the chain [14].

Finally, concordance studies between clinical and neuropathological

*Corresponding author: Richard J Kryscio, Professor, University of Kentucky Alzheimer's Disease Center, Room 230, Sanders Brown Center on Aging, 800 South Limestone Street, Lexington, Kentucky, USA, Tel: +1-859-257-4064, E-mail: Kryscio@email.uky.edu

Received December 07, 2012; Accepted December 10, 2012; Published December 17, 2012

Citation: Kryscio RJ, Abner EL (2013) Are Markov and semi-Markov Models Flexible Enough for Cognitive Panel Data? J Biomet Biostat 4:e122. doi:10.4172/2155-6180.1000e122

Copyright: (c) 2013 Kryscio RJ, et al. This is an open-access article distributed under the terms of the Creative Commons Attribution License, which permits unrestricted use, distribution, and reproduction in any medium, provided the original author and source are credited. 
Citation: Kryscio RJ, Abner EL (2013) Are Markov and semi-Markov Models Flexible Enough for Cognitive Panel Data? J Biomet Biostat 4:e122. doi:10.4172/2155-6180.1000e122

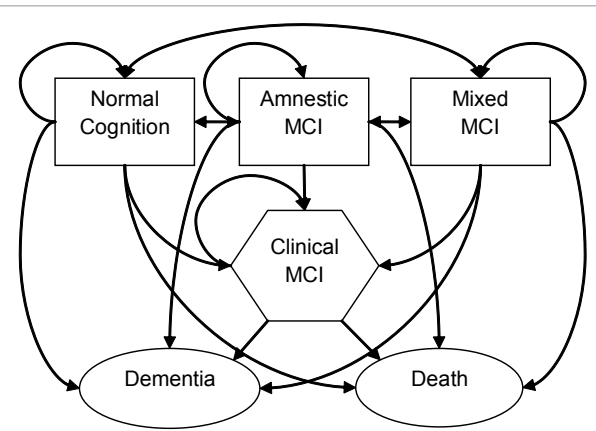

Figure 1: Flow diagram for a Markov chain illustrating the back flow among transient states: normal cognition, Amnestic and Mixed $\mathrm{MCl}$ are based on cognitive test results. Clinical $\mathrm{MCl}$ is based on several criteria. This state, dementia, and death are considered to be absorbing state [13]

diagnoses show that misclassification of the etiology of clinical impairments is common [15]. The risk factors for pure Alzheimer's disease, for example, likely differ from a mixed dementia, involving both AD and Lewy body disease, both of which likely differ from those for vascular dementia. This etiological misclassification tends to dilute the effect of a risk factor, depending heavily on the correlation between the clinical and neuropathological diagnoses within a study.

In closing, with the current emphasis on discovering who is at risk for dementing diseases like $\mathrm{AD}$ well before dementia occurs, the modeling of risk factors for dementia relying on traditional tools of Markov and semi-Markov processes presents challenges to the biostatistician. Since AD is now the sixth leading cause of death in the United States, and since the number of cases is rising exponentially $[16,17]$, the problems outlined above are worth pursuing.

\section{Funding}

This research was partially funded with support from the following grants to the University of Kentucky's Center on Aging: R01 AG03865101A1 and P30 AG028383 from the National Institute on Aging, as well as a grant to the University of Kentucky's Center for Clinical and Translational Science, UL1TR000117, from the National Center for Advancing Translational Sciences.

\section{References}

1. Beekly DL, Ramos EM, van Belle G, Deitrich W, Clark AD, et al. (2004) The National Alzheimer's Coordinating Center (NACC) Database: an Alzheimer disease database. Alzheimer Dis Assoc Disord 18: 270-277.

2. Gelber RP, Launer LJ, White LR (2012) The Honolulu-Asia Aging Study: epidemiologic and neuropathologic research on cognitive impairment. Curr Alzheimer Res 9: 664-672.

3. Foucher Y, Giral M, Soulillou JP, Daures JP (2007) A semi-Markov model for multistate and interval-censored data with multiple terminal events. Application in renal transplantation. Stat Med 26: 5381-5393.

4. Butler RW, Huzurbazar AV (1997) Stochastic network models for survival analysis. J Am Stat Assoc 92: 246-257.

5. Commenges D, Joly P (2004) Multi-state model for dementia, institutionalization, and death. Commun Stat Theory Methods 33: 1315-1326.

6. Yu L, Tyas SL, Snowdon DA, Kryscio RJ (2009) Effects of ignoring baseline on modeling transitions from intact cognition to dementia. Comput Stat Data Anal 53: $3334-3343$
7. Bateman RJ, Xiong C, Benzinger TL, Fagan AM, Goate A, et al. (2012) Clinica and biomarker changes in dominantly inherited alzheimer's disease. $\mathrm{N}$ Engl J Med 367: 795-804.

8. Jack CR Jr, Knopman DS, Jagust WJ, Shaw LM, Aisen PS, et al. (2010) Hypothetical model of dynamic biomarkers of the Alzheimer's pathological cascade. Lancet Neurol 9: 119-128.

9. Kryscio RJ, Schmitt FA, Salazar JC, Mendiondo MS, Markesbery WR (2006) Risk factors for transitions from normal to mild cognitive impairment and dementia. Neurology 66: 828-832.

10. Williams JW, Plassman BL, Burke J, Holsinger T, Benjamin S (2010) Preventing Alzheimer's disease and cognitive decline. AHRQ Publication No. 10-E005.

11. Abner EL, Kryscio RJ, Cooper GE, Fardo DW, Jicha GA, et al. (2012) Mild cognitive impairment: statistical models of transition using longitudinal clinical data. Int J Alzheimers Dis 2012: 291920.

12. Salazar JC, Schmitt FA, Yu L, Mendiondo MM, Kryscio RJ (2007) Shared random effects analysis of multi-state Markov models: application to a longitudinal study of transitions to dementia. Stat Med 26: 568-580.

13. Song C, Kuo L, Derby CA, Lipton RB, Hall CB (2011) Multi-stage transitional models with random effects and their application to the Einstein aging study. Biom J 53: 938-955.

14. Yu L, Griffith WS, Tyas SL, Snowdon DA, Kryscio RJ (2010) A nonstationary Markov transition model for computing the relative risk of dementia before death. Stat Med 29: 639-648.

15. Beach TG, Monsell SE, Phillips LE, Kukull W (2012) Accuracy of the clinical diagnosis of Alzheimer disease at National Institute on Aging Alzheimer Disease Centers, 2005-2010. J Neuropathol Exp Neurol 71: 266-273.

16. Brookmeyer R, Evans DA, Hebert L, Langa KM, Heeringa SG, et al. (2011) National estimates of the prevalence of Alzheimer's disease in the United States. Alzheimers Dement 7: 61-73.

17. Moschetti K, Cummings PL, Sorvillo F, Kuo T (2012) Burden of Alzheimer's disease-related mortality in the United States, 1999-2008. J Am Geriatr Soc 60: $1509-1514$. 